\title{
KAJIAN MOBILITAS MAHASISWA INDEKOST DI KOTA SINGARAJA(STUDI KASUS MAHASISWA SEMESTER AKHIR UNIVERSITAS PENDIDIKAN GANESHA TAHUN 2017)
}

\author{
Tina Puspita Sari Nasution ${ }^{1}$, Putu Indra Christiawan 2*
}

Pendidikan Geografi, Universitas Pendidikan Gannesha, Indonesia

\section{A R T I C L E I N F O \\ Article history: \\ Received 22 Desember 2018 \\ Received in revised form 10Februari 2018 \\ Accepted 12 Maret 2018 \\ Available online 31Maret} 2018

Kata Kunci:

Mobilitas

frekuensi

jarak

indekost

Keywords:

Mobility

Frequency

Distance

indeknst

agama.

\begin{abstract}
A B S T R A K
Penelitian ini dilaksanakan di Kota Singaraja dengan tujuan: (1) mendeskripsikan frekuensi mobilitas mahasiswa indekost semester akhir (2) menganalisis pengaruh jarak daerah asal terhadap frekuensi mobilitas mahasiswa indekost semester akhir (3) menjelaskan faktor individu yang berkonstribusi terhadap tinggi-rendahnya frekuensi mobilitas mahasiswa indekost semester akhir. Penelitian dirancang sebagai penelitian deskriptif,korelasional, menggunakan teknik snowball sampling. Pengumpulan data menggunakan metode wawancara terstruktur,pencatatan dokumen.Hasil penelitian menunjukkan bahwa (1). Frekuensi mobilitas mahasiswa indekost semester akhir dalam melakukan mobilitas ke daerah asal yaitu 3 sampai 4 kali sebulan (2). Pengaruh jarak daerah asal terhadap frekuensi mobilitas mahasiswa indekost semester akhir adalah berkorelasi negatif, semakin jauh jarak daerah asal mahasiswa indekost, semakin kecil frekuensi mobilitas mahasiswa (3). Faktor individu yang turut berkontribusi terhadap tinggi-rendahnya frekuensi mobilitas mahasiswa indekost semester akhir di Kota Singaraja yang paling dominan adalah kehabisan uang saku, kegiatan upacara
\end{abstract}

\section{A B S T R A C T}

This research is conducted in Singaraja with the intention: (1) Analyze the frequency of end-level student living in boardroom in Singaraja City (2) Describe the effect of distance the origin region to mobility frequency of the end-level in boardroom in Singaraja City (3) Explain what individual factors contributed to the high and low frequencies mobility of the student and-level living in boardroom in Singaraja City. This research is designed as descriptive and predictive research using snowball sampling technique. Data collection using structured interview method, document recording. Which is than analyzed with descriptive qualitative analysis.The result of the research shows that (1) The Frequency of mobility student end-level living in the boardroom in Singaraja City in doing mobility to the area of origin to that is 3 to 4 times a month (2) Influence of distance to area of origin to frequence mobility of student end-level in Singaraja City is negatively coreltide, that is, the smaller the frequence of student mobility (3) The Individual factor that contribute frequence of mobility of the dominant boardroom Singaraja City which most contribute to the high and low frequence of mobility is due to running out of pocket money and activities Religius ceremony.

\footnotetext{
* Corresponding author.

E-mail addresses:tina58810@gamil.com (Penulis Pertama), putu.ic87@gmail.com (Penulis Kedua)
} 


\section{Pendahuluan}

Geografi penduduk pada hakikatnya mempelajari penduduk dalam kaitannya dengan ruang huni manusia.. Kawi ( dalam Aprillia, 2013) menyatakan bahwa, geografi penduduk adalah suatu studi tentang penduduk dan bumi sebagai tempat kehidupannya, jumlah karakteristik, dan dinamika penduduk serta kaitannya dengan sosial, ekonomi, dan lingkungan dengan menggunakan pendekatan ekologi dalam geografi. Dinamika penduduk terjadi karena adanya fertilitas, mortalitas dan mobilitas penduduk. Peranan mobilitas penduduk terhadap laju pertumbuhan penduduk antara wilayah berbeda-beda, sehingga selalu menarik untuk dipelajari. Mobilitas penduduk telah ada sejak manusia itu ada di permukaan bumi. Mobilitas dilakukan untuk mempertahankan hidup dan disebabkan karena adanya kesenjangan antara satu wilayah dengan wilayah yang lain (Ubro, Krisnata, \& Wiji Nogroho, 2017).

Mobilitas penduduk memiliki kaitan erat dengan pembangunan, sebab mobilitas penduduk merupakan bagian integral proses pembangunan secara keseluruhan, artinya tidak ada pembangunan tanpa mobilitas penduduk dan begitu pula sebaliknya tidak ada mobilitas penduduk tanpa adanya pembanguan. Pembangunan diartikan sebagai proses perubahan yang berlangsung secara sadar, terencana, dan berkelanjutan dengan sasaran utamanya untuk meningkatkan kesejahteraan hidup manusia atau masyarakat suatu bangsa (Agusta, 2013). Pada pihak lain intensitas pembangunan.Perkembangan kota menyebabkan pusat kota menjadi daya tarik masyarakat sekitar, sehingga banyak pendatang yang masuk dengan berbagai tujuan, yaitu untuk bekerja dan juga untuk melanjutkan pendidikan. Kota Singaraja merupakan bagian wilayah administrasi Kabupaten Buleleng. Kota Singaraja dikatakan sebagai pusat dari Provinsi Bali di bagian utara, dengan karakteristik sebagai Kota Pendidikan (Dinas Pendidikan Pemkab Buleleng, 2014). Kota Pendidikan merupakan penghargaan terhadap sebuah kota yang ditandai dengan adanya dominasi institusi pendidikan dan fasilitas pendidikan. Dominasi institusi pendidikan akan tercermin pada jumlah institusi pendidikan, kemudian perbandingan institusi negeri maupun swasta di suatu daerah dan juga perbandingan antara jumlah penduduk kota dengan jumlah institusi yang ada. Jumlah penduduk Kota Singaraja berjumlah 97.570 jiwa (Badan Pusat Statistik Kabupaten Buleleng, 2011) dan jumlah institusi sekolah di Kota Singaraja akan dirinci pada Tabel 1.

Tabel 1. Jumlah Institusi Pendidikan di Kota Singaraja

\begin{tabular}{cccc}
\hline No & Institusi & Jenis institusi & Jumlah \\
\hline $\mathbf{1 1}$ & & $(\mathbf{3})$ & $(\mathbf{4})$ \\
$\mathbf{1}$ & SD & Negeri & 38 \\
& & Swasta & 8 \\
$\mathbf{2}$ & SMP & Negeri & 7 \\
& & Swasta & 10 \\
$\mathbf{3}$ & SMA & Negeri & 4 \\
& & Swasta & 8 \\
$\mathbf{4}$ & SMK & Negeri & 3 \\
& & Swasta & 5 \\
$\mathbf{5}$ & Perguruan Tinggi & Negeri & 2
\end{tabular}


Swasta 4

Total

89

Sumber: Dinas Pendidikan Kabupaten Buleleng, 2011

Berdasarkan Tabel 1. Kota Singaraja memiliki jumlah institusi negeri maupun swasta mencapai 89 instisusi dengan perbandingan jumlah institusi negeri 54 buah dan institusi swasta 34 buah. Keberadaan dari institusi pendidikan merupakan cerminan bagi suatu daerah dijadikan sebagai kota pendidikan.Beragamnya institusi pendidikan di Kota Singaraja memberikan pengaruh yang positif bagi perkembangan Kota Singaraja. Eksistensi perguruan tinggi menandakan adanya pertumbuhan dalam bidang pendidikan. Universitas Pendidikan Ganesha merupakan salah satu Perguruan tinggi negeri di kota Singaraja sebagai universitas pemberi keleluasaan bagi calon mahasiswa untuk memilih jurusan yang ada, baik di bidang pendidikan maupun non pendidikan. Universitas Pendidikan Ganesha memiliki 7 Fakultas yaitu Fakultas Hukum dan Ilmu Sosial (FHIS), Fakultas Matematika dan Ilmu Pengetahuan Alam (FMIPA), Fakultas Bahasa dan Seni (FBS), Fakultas Ilmu Pendidikan (FIP), Fakultas Olahraga dan Kesehatan (FOK), Fakultas Teknik dan Kejuruan (FTK), serta Fakultas Ekonomi (FE), dan 1 Pasca Sarjana, selanjutnya di setiap Fakultas tersebut terdiri lagi dari berbagai jurusan.

Mahasiswa yang umumnya melanjutkan pendidikan di Kota Singaraja datang dari berbagai wilayah yang berbeda-beda, baik itu berasal dari Bali maupun dari luar Bali. Kehadiran mahasiswa mengakibatkan munculnya usaha rumah kos, terutama diperuntukkan bagi mahasiswa pendatang. Rumah kost diartikan sebagai suatu tempat tinggal yang disewakan kepada pihak lain dengan fasilitas-fasilitas tertentu dengan harga yang lebih terjangkau daripada di hotel/penginapan (Damayanti \& Holil, 2016)(Damayanti, 2016). Setiap pendatang selalu mencari tempat tinggal untuk memudahkan akses mereka ke kampus. Tempat tinggal yang biasa di cari adalah yang berdekatan dengan kampus, tujuannya menyelesaikan studi.

Banyak hal yang menjadi pertimbangan dalam memilih kost misalnya ada yang memilih kost dengan lokasi yang strategis seperti dekat dengan kampus, tempat makan, warnet, fotocopy, shooping center, ataupun tempat-tempat hiburan lainnya(Hajar, Susilawati, \& Nilakusmawati, 2015) Pemilihan rumah kos umumnya didasarkan pada tingkat kenyamanan dan jarak akses ke kampus.. Rumah kos yang dekat dengan warung makan juga mempermudah mahasiswa memenuhi kebutuhan makan. Selain itu pemilihan rumah kos yang dilakukan oleh mahasiswa, yaitu dengan melihat fasilitas rumah kos, pada umumnya fasilitas rumah kos adalah tempat tidur, lemari, meja belajar dan kamar mandi, ada juga yang isi dapur. Fasilitas rumah kos juga berbeda-beda, ada yang kamar mandi dalam ada juga kamar mandi luar yaitu kamar mandi umum (Utomo, 2009).

Kehadiran mahasiswa juga menyebabkan peningkatan mobilitas. Hal ini dipengaruhi oleh tersedianya prasarana transportasi dan komunikasi yang memadai dan modern. Rata-rata mahasiswa luar kota setelah mengenal daerah tujuan, mereka membawa sepeda motor dari daerah asalnya. Hal ini dilakukan dengan alasan memudahkan mobilitas mereka dari kampus ke rumah kos atau sebaliknya dari rumah 
kos ke kampus dan juga memudahkan mobilitas untuk pulang ke daerah asal. Mahasiswa semester akhir umumnya memiliki kecenderungan sering melakukan mobilitas. Hal ini dikarenakan sudah tidak mengikuti perkuliahan. Berdasarkan observasi awal yang dilakukan terdapat 30 orang mahasiswa indekos semester akhir Undiksha yang tinggal di rumah kos, 23 diantaranya setiap minggu melakukan mobilitas. Seringnya mahasiswa melakukan mobilitas tersebut akan menimbulkan beberapa dampak.

Dampak negatif yang ditimbulkan karena sering melakukan mobilitas adalah keselamatan dari pelaku mobilitas tersebut. Banyaknya yang melakukan mobilitas mengakibatkan kemacetan dijalan raya, yang bisa berdampak pada kecelakaan. Apalagi dilihat jalan dari Bali utara menuju ke Bali selatan yang kondisi jalannya tidak baik karena banyak jalan rusak, begitu juga dengan daerah lainnya. Juga biaya yang dibutuhkan perlu untuk diperkirakan, yaitu, bensin dan kerusakan kendaraan karena sering dibawa dalam perjalanan jauh, dan dampak dari mahasiswa semester akhir sering melakukan mobilitas adalah dapat menghambat penyelesaian skripsi.

Mahasiswa yang sering melakukan mobilitas masih sulit untuk ditentukan, mahasiswa yang sering melakukan mobilitas tersebut yang jarak rumahnya dekat dari Kota Singaraja atau jarak rumahnya jauh dari Kota Singaraja. Hal ini dikarenakan jarak berpengaruh terhadap frekuensi mobilitas penduduk, dalam teori mobilitas penduduk, hukum migrasi oleh Revenstein disebutkan bahwa migrasi cenderung menempuh jarak dekat, dan apabila daerah tujuan semakin jauh, frekuensi migran menuju kedaerah tersebut semakin kecil (Mantra, 2000).

Besar kecilnya arus mobilitas juga disebabkan oleh faktor individu, karena individu yang menilai positif dan negatifnya suatu daerah, dan individu juga yang memutuskan untuk melakukan mobilitas atau tidak. Tiap-tiap individu mempunyai penilaian yang berbeda terhadap daerah asal dan daerah tujuan. Ada yang menganggap bahwa hidup di daerah asal sangat menyenangkan, sebaliknya orang lain menganggap bahwa tinggal di daerah asal sangat membosankan, begitu pula di daerah tujuan. Jadi, faktor individu juga merupakan salah satu faktor untuk mengambil keputusan dalam melakukan mobilitas (Mantra, 2000).

Secara umum anak kos yang cenderung sering pulang adalah anak kos yang jarak rumahnya tidak terlalu jauh dari kota Singaraja, masih berada di Buleleng. Akan tetapi hal ini belum bisa dipastikan, karena terdapat juga anak kos yang asalnya di luar Kabupaten Buleleng bahkan lebih sering pulang dibandingkan dengan anak kos yang daerah asalnya dari dalam Kabupaten Buleleng. Berdasarkan uraian tersebut dipandang penting untuk meneliti tentang "Kajian Mobilitas Mahasiswa Indekost Di Kota Singaraja (Studi Kasus Mahasiswa Semester Akhir Universitas Pendidikan Ganesha Tahun 2017)".

\section{Metode}

Penelitian ini dilakukan di Kota Singaraja, objek dalam penelitian ini adalah mobilitas mahasiswa indekost di Kota Singaraja. Berkenaan dengan itu subjek dalam penelitian ini adalah mahasiswa indekost semester akhir Undiksha di Kota Singaraja. Penelitian ini menggunakan racangan penelitian deskriptif dan korelasional. Data yang 
digunakan adalah data primer dan sekunder. Data sekunder bersumber dari Badan Pusat statistik Kabupaten Buleleng. Data primer yang telah dikumpulkan selanjutnya akan dianalisis menggunakan analisis deskriptif kualitatif dan kuantitatif dengan menggunakan pendekatan keruangan. Pengaruh jarak ke daerah asal terhadap frekuensi mobilitas mahasiswa indekost semester akhir di Kota Singaraja dianalisis dengan regresi linier sederhana.

\section{Hasil dan pembahasan}

a. Daerah Asal Mahasiswa indekost

Tabel 2.Daerah asal mahasiswa indekost semester akhir di Kota Singaraja

\begin{tabular}{|c|c|c|c|c|c|c|c|c|c|c|c|c|c|c|c|c|c|}
\hline \multirow[t]{3}{*}{ No } & \multirow{3}{*}{$\begin{array}{l}\text { Dae- } \\
\text { rah } \\
\text { asal }\end{array}$} & \multicolumn{14}{|c|}{ Mahasiswa indekost menurut fakultas } & \multirow{3}{*}{$\begin{array}{l}\text { Jum - } \\
\text { lah }\end{array}$} & \multirow{3}{*}{$\begin{array}{c}\text { Per- } \\
\text { sentase } \\
(\%)\end{array}$} \\
\hline & & \multicolumn{2}{|c|}{ Fhis } & \multicolumn{2}{|c|}{ Fok } & \multicolumn{2}{|c|}{ Ftk } & \multicolumn{2}{|c|}{ Fmipa } & \multicolumn{2}{|c|}{ Fip } & \multicolumn{2}{|c|}{$\mathbf{F e}$} & \multicolumn{2}{|c|}{ Fbs } & & \\
\hline & & $\mathbf{N}$ & $\%$ & $\mathbf{N}$ & $\%$ & $\mathbf{N}$ & $\%$ & $\mathbf{N}$ & $\%$ & $\mathbf{N}$ & $\%$ & $\mathbf{N}$ & $\%$ & $\mathbf{N}$ & $\%$ & & \\
\hline 1 & A & 0 & 0 & 2 & 40 & 2 & 50 & 7 & 41 & 14 & 45 & 9 & 33 & 5 & 23 & 39 & 35,45 \\
\hline 2 & B & 3 & 60 & 3 & 60 & 2 & 50 & 9 & 53 & 17 & 55 & 15 & 48 & 16 & 76 & 65 & 59,09 \\
\hline 3 & $\mathrm{C}$ & 2 & 40 & 0 & 0 & 0 & 0 & 1 & 6 & 0 & 0 & 3 & 11 & 0 & 0 & 6 & 5,45 \\
\hline 4 & $\mathrm{D}$ & 0 & 0 & 0 & 0 & 0 & 0 & 0 & 0 & 0 & 0 & 0 & 0 & 0 & 0 & 0 & 0 \\
\hline & nlah & 5 & 100 & 5 & 100 & 4 & 100 & 17 & 100 & 31 & 100 & 27 & 100 & 21 & 100 & 110 & 100 \\
\hline
\end{tabular}

Sumber : Analisis data sekunder , 2017

Keterangan:

A : Di luar Kota Singaraja, masih dalam Kabupaten Buleleng

B : Di luar Kabupaten Buleleng, masih dalam Provinsi Bali

C : Di luar Provinsi Bali, masih dalam negeri

D : Di luar negeri

Dari tabel 2. diketahui bahwa daerah asal mahasiswa indekost semester akhir di Kota Singaraja paling banyak berasal dari luar Kabupaten Buleleng masih dalam Provinsi Bali yaitu 59\% sedangkan dari luar negeri hanya $0 \%$. Hal ini berlaku juga pada masing-masing fakultas, rata-rata daerah asal mahasiswa indekost semester akhir setiap fakultas di Undiksha berasal dari luar Kabupaten Buleleng masih dalam Provinsi Bali.

b. Kelurahan/Desa lokasi indekost

Tabel 3.Kelurahan/Desa lokasi indekost mahasiswa semester akhir Di KotaSingaraja

\begin{tabular}{llcc}
\hline No & \multicolumn{1}{c}{ Kelurahan } & \multicolumn{2}{c}{ Jumlah } \\
\cline { 3 - 4 } & & $\mathbf{N}$ & Persentase (\%) \\
\hline $\mathbf{1}$ & Kaliuntu & 27 & 24,54 \\
$\mathbf{2}$ & Banjar Tegal & 16 & 14,54 \\
$\mathbf{3}$ & Banyuning & 8 & 7,27 \\
$\mathbf{4}$ & Banyuasri & 14 & 12,72 \\
$\mathbf{5}$ & Banjar Jawa & 14 & 12,72 \\
$\mathbf{6}$ & Sambangan & 13 & 11,8 \\
$\mathbf{7}$ & Bakti Seraga & 12 & 10,9 \\
$\mathbf{8}$ & Astina & 1 & 0,90
\end{tabular}




\begin{tabular}{llcc}
$\mathbf{9}$ & Paket Agung & 2 & 1,81 \\
$\mathbf{1 0}$ & Liligundi & 1 & 0,90 \\
$\mathbf{1 1}$ & Kampung Bugis & 1 & 0,90 \\
$\mathbf{1 2}$ & Kendran & 1 & 0,90 \\
\hline & Jumlah & $\mathbf{1 1 0}$ & $\mathbf{1 0 0}$ \\
\hline
\end{tabular}

Sumber : Analisis data sekunder , 2017

Tabel 3. memperlihatkan bahwa alamat rumah kos mahasiswa indekost semester akhir di Kota Singaraja masih terdapat di dalam Kota Singaraja yaitu di kelurahan Kaliuntu sebanyak 24,5\%. Mahasiswa. Paling sedikit terdapat di Liligundi, Kendran, Astina dan Kampungbugis, hanya terdapat 0,90\% mahasiswa. Hal ini di karenakan Kelurahan Kaliuntu berada di pusat Kota Singaraja, dekat dengan kampus, juga dekat dengan tukang print, tempat makan, dan juga banyak tersedia rumah kosan, sehingga kebanyakan mahasiswa memilih rumah kos di Kaliuntu.

c. Frekuensi Mobilitas

Tabel 4.

Frekuensi mobilitas mahasiswa indekost semester akhir Undiksha Di Kota Singaraja

\begin{tabular}{|c|c|c|c|c|c|c|c|c|c|c|c|c|c|c|c|c|c|}
\hline \multirow{3}{*}{\multicolumn{2}{|c|}{$\begin{array}{c}\text { No Frekuensi } \\
\text { mobilitas } \\
\text { mahasiswa } \\
\text { indekost } / \\
\text { bulan }\end{array}$}} & \multicolumn{14}{|c|}{ Mahasiswa indekost Menurut Fakultas } & \multirow[t]{3}{*}{$\begin{array}{l}\text { Jum- } \\
\text { lah }\end{array}$} & \multirow{3}{*}{$\begin{array}{c}\text { Persen } \\
\text { tase } \\
(\%)\end{array}$} \\
\hline & & \multicolumn{2}{|c|}{ FHIS } & \multicolumn{2}{|c|}{ FOK } & \multicolumn{2}{|c|}{ FIP } & \multicolumn{2}{|c|}{ FMIPA } & \multicolumn{2}{|c|}{ FTK } & \multicolumn{2}{|c|}{$\mathrm{FE}$} & \multicolumn{2}{|c|}{ FBS } & & \\
\hline & & $\mathbf{N}$ & $\%$ & $\mathbf{N}$ & $\%$ & $\mathbf{N}$ & $\%$ & $\mathbf{N}$ & $\%$ & $\mathbf{N}$ & $\%$ & $\mathbf{N}$ & $\%$ & $\mathbf{N}$ & $\%$ & & \\
\hline 1 & 0 & 0 & 0 & 0 & 0 & 2 & 6,5 & 0 & 0 & 0 & 0 & 0 & 0 & 1 & 5 & 3 & 2,7 \\
\hline 2 & 1kali & 1 & 20 & 2 & 40 & 3 & 9,7 & 1 & 6 & 0 & 0 & 5 & 18 & 0 & 0 & 12 & 10,9 \\
\hline 3 & 2 kali & 2 & 40 & 1 & 20 & 3 & 9,7 & 9 & 53 & 2 & 50 & 4 & 15 & 2 & 10 & 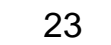 & 20,9 \\
\hline 4 & 3 kali & 0 & 0 & 0 & 0 & 10 & 32 & 4 & 23 & 0 & 0 & 8 & 30 & 4 & 19 & 2 & 23,6 \\
\hline 5 & 4 kali & 1 & 20 & 2 & 40 & 10 & 32 & 1 & 6 & 2 & 50 & 4 & 15 & 7 & 33 & 27 & 24,54 \\
\hline \multirow[t]{2}{*}{6} & 5 kali & 1 & & 0 & 0 & 1 & 3,2 & 2 & 12 & 0 & 0 & 2 & 7 & 4 & 19 & 10 & 9,09 \\
\hline & & 0 & $\begin{array}{r}20 \\
0\end{array}$ & 0 & 0 & 2 & & 0 & & 0 & U & 3 & 1 & 3 & 4 & & \\
\hline \multirow[t]{2}{*}{7} & 7 kali & 0 & 0 & 0 & 0 & 0 & 0 & 0 & 0 & 0 & 0 & 1 & 4 & 0 & 0 & 1 & 0,90 \\
\hline & Jumlah & 5 & 100 & & 00 & 31 & 100 & 171 & 100 & 4 & 100 & 27 & 100 & 21 & 100 & 110 & 100 \\
\hline
\end{tabular}

Sumber : Analisi data sekunder, 2017

Berdasarkan hasil penelitian dapat diketahui bahwa frekuensi mobilitas mahasiswa indekost semester akhir di Kota Singaraja melakukan mobilitas ke daerah asal yaitu 3 sampai 4 kali dalam sebulan. 3 kali sekitar 23\% dan 4 kali sekitar $24 \%$. Hal tersebut disebabkan karena daerah asal mahasiswa indekost semester akhir tidak terlalu jauh dari Kota Singaraja. Hasil penelitian ini berbeda dengan temuan dari Astrawan, (2012) yang meneliti tentang mobilitas harian pedagang sayur pasar Anyar Singaraja, mengemukakan bahwa rata-rata frekuensi mobilitas yang dilakukan respondennya yaitu, 6 kali dalam seminggu 
d. Jarak Daerah Asal

Tabel 5. Jarak daerah asal mahasiswa indekost ke Kota Singaraja

\begin{tabular}{|c|c|c|c|c|c|c|c|c|c|c|c|c|c|c|c|c|c|}
\hline \multirow[t]{3}{*}{ No } & \multirow[t]{3}{*}{ Jarak $(\mathrm{Km})$} & \multicolumn{15}{|c|}{ Mahasiswa indekost Menurut Fakultas } & \multirow{3}{*}{$\begin{array}{c}\text { Persen } \\
\text { tase } \\
(\%)\end{array}$} \\
\hline & & \multicolumn{2}{|c|}{ Fhis } & \multicolumn{2}{|c|}{ Fok } & \multicolumn{2}{|c|}{ Ftk } & \multicolumn{2}{|c|}{ Fmipa } & \multicolumn{2}{|c|}{ Fip } & \multicolumn{2}{|r|}{$\mathbf{F e}$} & \multicolumn{2}{|c|}{ Fbs } & \multirow{2}{*}{$\begin{array}{l}\text { Jum- } \\
\text { lah }\end{array}$} & \\
\hline & & $\Lambda$ & $\%$ & $\mathbf{N}$ & $\%$ & $\mathbf{N}$ & $\%$ & $\mathbf{N}$ & $\%$ & $\mathbf{N}$ & $\%$ & $\mathbf{N}$ & $\%$ & $\mathbf{N}$ & $\%$ & & \\
\hline 1 & $<50$ & & 0 & 2 & 40 & 2 & 50 & 5 & 29 & 6 & 19 & 8 & 30 & 8 & 38 & 30 & 27,27 \\
\hline 2 & $50-75$ & & 40 & 0 & 0 & 1 & 25 & 1 & 6 & 10 & 32 & 5 & 19 & 3 & 14 & 22 & 20 \\
\hline 3 & $75-100$ & & 60 & 2 & 40 & 2 & 25 & $\begin{array}{l}1 \\
0\end{array}$ & 59 & 14 & 45 & $\begin{array}{l}1 \\
1\end{array}$ & 41 & $\begin{array}{l}1 \\
0\end{array}$ & 48 & 52 & 47,27 \\
\hline 4 & $>100$ & & 0 & 1 & 20 & 0 & 0 & 1 & 6 & 2 & 6 & 2 & 7 & 0 & 0 & 6 & 5,45 \\
\hline & Jumlah & 5 & 1100 & 5 & 100 & & 100 & 17 & 100 & 31 & 100 & 27 & 100 & 21 & 100 & 110 & 100 \\
\hline
\end{tabular}

Sumber: Analisis data sekunder, 2017

e. Pengujian Hasil Hipotesis

Pada penelitian rumusan masalah kedua ini akan dianalisis dengan menggunakan

regresi linear sederhana

Hasil regresi linier sederhana disajikan sebagai berikut:

a. Hipotesis :

Ho : tidak terdapat pengaruh jarak mahasiswa indekost ke daerah asal terhadap frekuensi mobilitas mahasiswa indekost semester akhir di Kota Singaraja.

H1 : terdapat pengaruh jarak mahasiswa indekost ke daerah asal terhadap frekuensi mobilitas mahasiswa indekost semester akhir di Kota Singaraja.

b. Pengujian Hipotesis

Sebelum melakukan analisis dengan regresi linear sederhana, terlebih dahulu data yang diperoleh di lapangan harus memenuhi uji prasyarat yaitu sebagai berikut :

1) Uji Normalitas

Hipotesis :

a) Ho : Data frekuensi mobilitas mahasiswa berdistribusi normal

H1 : Data frekuensi mobilitas mahasiswa tidak berdistribusi normal

Ho : Data jarak daerah asal mahasiswa berdistribusi normal

H1 : Data jarak daerah asal mahasiswa tidak berdistribusi normal

Uji normalitas kedua data di atas dilakukan dengan spss dan diperoleh hasil sebagai berikut 
One-Sample Kolmogorov-Smirnov Test

\begin{tabular}{|ll|r|r|}
\hline & & frekuensi & \multicolumn{1}{c|}{ Jarak } \\
\hline $\mathrm{N}$ & & 110 & 110 \\
Normal Parameters ${ }^{\mathrm{a}}$ & Mean & 3.1727 & 75.5182 \\
& Std. & 1.51360 & $2.11689 \mathrm{E}$ \\
& Deviation & 1 \\
Most Extreme Differences & Absolute & .127 & .120 \\
& Positive & .127 & .090 \\
& Negative & -.126 & -.120 \\
Kolmogorov-Smirnov Z & & 1.335 & 1.257 \\
Asymp. Sig. (2-tailed) & & .057 & .085 \\
\hline
\end{tabular}

a. Test distribution is Normal.

Dasar pengambilan keputusan dalam uji normalitas Kolmogorov- Smirnov di atas adal ah sebagai berikut:

1.Jika nilai sig $>0.05$, maka Ho diterima yaitu data berdistribusi normal

2.Jika nilai sig $<0.05$, maka Ho ditolak yaitu data tidak berdistribusi normal.

Berdasarkan dari tabel uji normalitas diatas, maka diperoleh hasil bahwa :

1. Nilai signifikansi untuk data frekuensi mobilitas mahasiswa adalah 0.057, dan jarak daerah asal mahasiswa adalah 0.085. terlihat bahwa signifikasi kedua data tersebut $>0.05$ sehingga dapat diambil kesimpulan bahwa ke- 2 data berdistribusi normal.

c. Setelah data berdistribusi normal, uji prasyarat selanjutnya adalah uji linearitas dan keberartian arah regresi. Berikut hasil uji linearitas dengan spss.

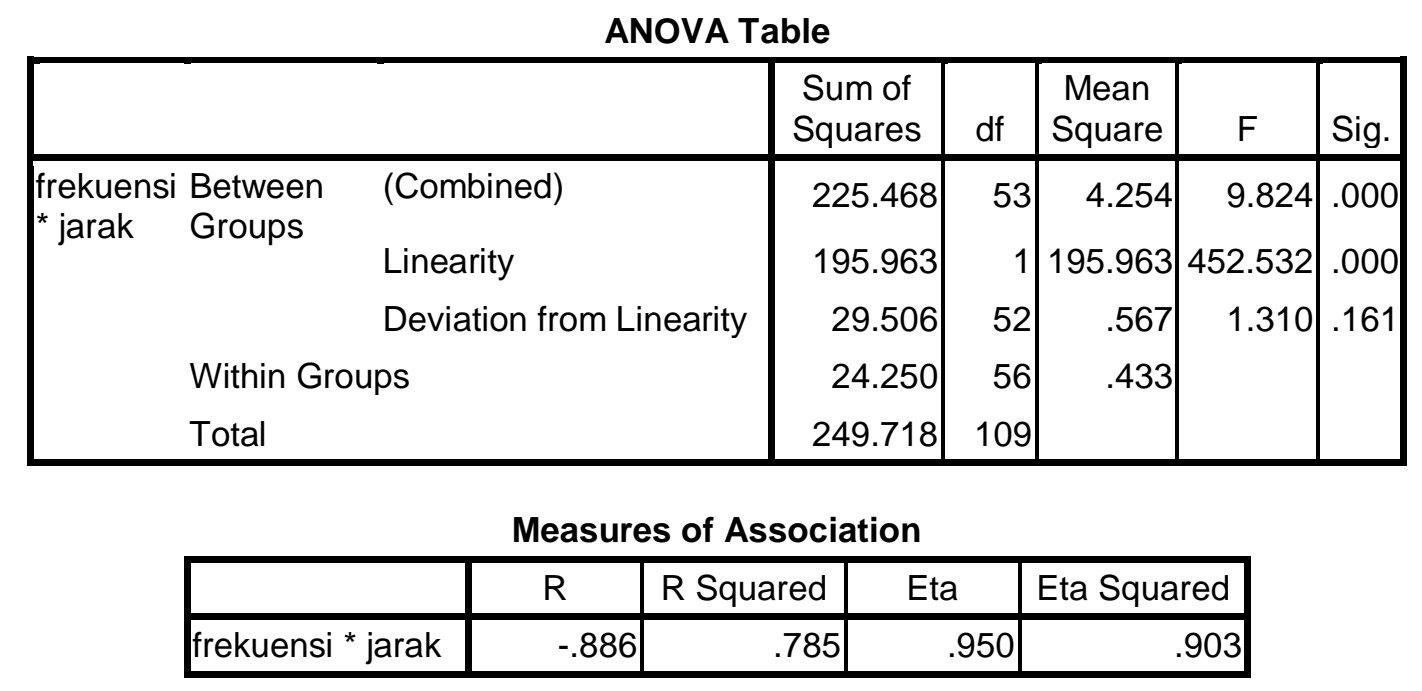

Berdasarkan hasil yang diperoleh dari uji linearitas dan keberartian arah regresi dengan spss, yaitu perhatikan tabel ANOVA. 
a) Perhatikan bahwa signifikansi dari Linearity adalah sebesar 0.00, ini berarti sig. linearity< 0.05, hal ini menunjukkan bahwa arah regresi nya signifikan (ada hubungan yang signifikan antara jarak daerah asal mahasiswa terhadap frekuensi mobilitas mahasiswa.

b) Selanjutnya, perhatikan signifikasi Deviation from linearity adalah sebesar 0.161, dengan kata lain sig. Deviation from linearity $>0.05$, hal ini menunjukkan bahwa data di atas bersifat linear.

c) Kemudian, perhatikan tabel Measure of Association diatas, nilai dari $\mathrm{R}=-0.886 \mathrm{ini}$ berarti bahwa jarak daerah asal mahasiswa dan frekuensi mobilitas mahasiswa berkorelasi negatif atau dengan kata lain jika jarak daerah asal mahasiswa meningkat maka frekuensi mobilitas mahasiswa semakin menurun. Perhatikan juga nilai dari R2 $=0.785$, ini berarti bahwa78,5\% perubahan frekuensi mobilitas mahasiswa dipengaruhi oleh jarak daerah asal mahasiswa.

Pengujian hipotesis.

Setelah kedua syarat diatas terpenuhi, selanjutnya dilakukan uji regresi linear sederhana dengan menggunakan spss, dan diperoleh hasil sebagai berikut

\section{Tabel 6,}

Uji normalitas kedua data di atas dilakukan dengan spss dan diperoleh hasil sebagai berikut:

\begin{tabular}{|c|c|c|c|c|c|c|c|c|c|c|c|c|c|c|c|c|c|}
\hline \multirow{3}{*}{ No } & \multirow{3}{*}{$\begin{array}{l}\text { Fak tor } \\
\text { Indi vidu }\end{array}$} & \multicolumn{14}{|c|}{ Mahasiswa indekost / Fakultas } & \multirow{3}{*}{$\begin{array}{l}\text { Jum- } \\
\text { lah }\end{array}$} & \multirow{3}{*}{$\begin{array}{c}\text { Persen } \\
\text { tase } \\
(\%)\end{array}$} \\
\hline & & \multicolumn{2}{|c|}{ FHIS } & \multicolumn{2}{|c|}{ FOK } & \multicolumn{2}{|c|}{ FIP } & \multicolumn{2}{|c|}{ FMIPA } & \multicolumn{2}{|c|}{ FTK } & \multicolumn{2}{|r|}{ FE } & \multicolumn{2}{|r|}{ FBS } & & \\
\hline & & $\mathbf{N}$ & $\%$ & $\mathbf{N}$ & $\%$ & $\mathbf{N}$ & $\%$ & $\mathbf{N}$ & $\%$ & $\mathbf{N}$ & $\%$ & $\mathbf{N}$ & $\%$ & $\mathbf{N}$ & $\%$ & & \\
\hline 1 & A & 2 & 40 & 2 & 40 & 16 & 52 & 7 & 41 & 1 & 25 & 9 & 33 & 7 & 33 & 44 & 40 \\
\hline 2 & B & 2 & 40 & 2 & 40 & 7 & 23 & 5 & 29 & 1 & 25 & 6 & 22 & 4 & 19 & 27 & 24,5 \\
\hline 3 & C & 0 & 0 & 0 & 0 & 2 & 6 & 1 & 6 & 1 & 25 & 2 & 7 & 3 & 14 & 9 & 8,18 \\
\hline 4 & D & 1 & 20 & 1 & 20 & 1 & 3 & 1 & 6 & 0 & 0 & 1 & 4 & 0 & 0 & 5 & 4,54 \\
\hline 5 & $E$ & 0 & 0 & 0 & 0 & 1 & 3 & 0 & 0 & 0 & 0 & 2 & 7 & 2 & 10 & 5 & 4,54 \\
\hline 6 & $\mathrm{~F}$ & 0 & 0 & 0 & 0 & 0 & 0 & 0 & 0 & 0 & 0 & 1 & 4 & 0 & 0 & 1 & 0,90 \\
\hline 7 & G & 0 & 0 & 0 & 0 & 3 & 10 & 2 & 12 & 1 & 25 & 4 & 15 & 4 & 19 & 14 & 12,72 \\
\hline 8 & $\mathrm{H}$ & 0 & 0 & 0 & 0 & 1 & 3 & 0 & 0 & 0 & 0 & 1 & 4 & 0 & 0 & 2 & 1,8 \\
\hline 9 & I & 0 & 0 & 0 & 0 & 0 & 0 & 1 & 6 & 0 & 0 & 0 & 0 & 0 & 0 & 1 & 0,9 \\
\hline 10 & $\mathrm{~J}$ & 0 & 0 & 0 & 0 & 0 & 0 & 0 & 0 & 0 & 0 & 1 & 4 & 1 & 5 & 2 & 1,8 \\
\hline & Imlah & 5 & 100 & 5 & 100 & 31 & 100 & 17 & 100 & 41 & 00 & 27 & 100 & 21 & 100 & 110 & 100 \\
\hline
\end{tabular}

Berdasarkan analisis pengaruh jarak 7 ke daerah asal terhadap frekuensi mobilitas mahasiswa indekost semester akhir di Kota Singaraja yang dihitung dengan menggunakan rumus regresi linier sederhana dapat diketahui bahwa nilai t hitung sebesar -19,842 dengan nilai signifikansi 0,00<0,05, ini berarti Ho ditolak dan H1 diterima, yang berarti bahwa diperoleh kesimpulan : "Terdapat pengaruh jarak 
mahasiswa indekost ke daerah asal terhadap frekuensi mobilitas mahasiswa indekost semester akhir di Kota Singaraja", pengaruh yang dihasilkan adalah berkorelasi negatif yaitu semakin jauh jarak daerah asal mahasiswa indekost maka semakin kecil frekuensi mobilitas mahasiswa.

Berbeda halnya dengan temuan dari Astrawan, (2012) yang meneliti tentang mobilitas harian pedagang sayur pasar anyar Singaraja, dari hasil penelitiannya diketahui bahwa jarak tidak mempengaruhi frekuensi mobilitas harian. Semakin jauh jarak tidak berarti jumlah frekuensi menjadi berkurang Faktor-faktor individu yang turut berkontribusi terhadap tinggi- rendahnya frekuensi mobilitas mahasiswa indekost semester akhir di Kota Singaraja

Berdasarkan hasil penelitian yang telah dilakukan ada beberapa faktor individu yang turut berkontribusi terhadap tinggi-rendahnya frekuensi mobilitas mahasiswa indekost di Kota Singaraja, yaitu kehabisan uang saku, rindu keluarga, penelitian skripsi didaerah asal, selain itu ada beberapa faktor lainnya yaitu, karena rindu pacar, ingin kumpul bersama teman, kegiatan upacara agama, kegiatan ukm jurusan, daerah asal dekat dari Kota Singaraja, daerah asal yang jauh, dan biaya pulang mahal. Diantara beberapa faktor tersebut yang paling berkontribusi terhadap tinggi-rendahnya frekuensi mobilitas adalah karena kehabisan uang saku. Faktor lain selain dari kehabisan uang saku yang menjadi faktor mahasiswa untuk melakukan mobilitas adalah karena kegiatan upacara agama, terdapat 12\% mahasiswa yang menjawab alasan pulang ke daerah asal karena upacara agama.

\section{Simpulan dan Saran}

Frekuensi mobilitas mahasiswa indekost semester akhir di Kota Singaraja dalam melakukan mobilitas ke daerah asal yaitu 3 sampai 4 kali dalam sebulan, 3 kali r 23\% dan 4 kali 24\%.Pengaruh jarak ke daerah asal terhadap frekuensi mobilitas mahasiswa indekost semester akhir di Kota Singaraja yang dihitung dengan menggunakan rumus regresi linier sederhana, dengan nilai signifikansi 0,00<0,05 ,berkorelasi negatif yaitu, semakin jauh jarak daerah asal mahasiswa indekost maka semakin kecil frekuensi mobilitas mahasiswa. Faktor-faktor individu yang turut berkontribusi terhadap tinggirendahnya frekuensi mobilitas mahasiswa indekost semester akhir di Kota Singaraja yang paling berkontribusi terhadap tinggi-rendahnya frekuensi mobilitas adalah karena kehabisan uang saku, selain dari kehabisan uang saku yang menjadi faktor individu mahasiswa untuk melakukan mobilitas adalah karena kegiatan upacara agama, terdapat sekitar 12\% mahasiswa yang menjawab alasan pulang ke daerah asal karena upacara agama. Dari hasil pengamatan yang telah dilakukan, maka dapat disarankan kepada masyarakat Kota Singaraja, khususnya yang menjual kebutuhan makanan bagi mahasiswa indekost, untuk bisa meminimalisir persediaan makanan yang akan di jual, apabila frekuensi mobilitas mahasiswa tinggi, agar jualannya bisa terjual habis.

Bagi Undiksha disarankan agar lebih memperhatikan mahasiswa yang sering melakukan mobilitas ke daerah asal, agar nantinya jika ada kegiatan dikampus dapat mengantisipasi mahasiswa yang harus dilibatkan pada kegiatan yang ada pada masingmasing fakultas. 


\section{Daftar Rujukan}

Agusta, A. (2013). Faktor Faktor Yang Mempengaruhi Mobilitas Penduduk Ke Desa Kota Bangun Dua Kecamatan Kota Bangun Kabupaten Kutai Kartanegara. Jurnal Pemerintahan, 1(2), 862-874.

Aprillia, K. Y. (2013). Migran Di Kota Negara Dan Faktor-Faktor Yang Mempengaruhinya (Kajian Geografi Penduduk). Jurnal Jurusan Pendidikan Geografi.

Astrawan, I. M. Y. S. (2012). Mobilitas Harian Pedagang Sayur Pasar Anyar Singaraja.

Badan Pusat Statistik Kabupaten Buleleng. (2011). Buleleng dalam angka.

Damayanti, F., \& Holil. (2016). Sistem Informasi Rumah Kost Berbasis Web dan Google Maps API. Jurnal Ilmiah Multitek Indonesia, 10(1), 19-27.

Dinas Pendidikan Pemkab Buleleng. (2014). Kota Singaraja dicanangkan sebagai Kota Pendidikan.

Hajar, S., Susilawati, M., \& Nilakusmawati, D. P. . (2015). Faktor Faktor Yang Mempengaruhi Keputusan Mahasiswa Dalam Memilih Rumah Kost. E-Jurnal Matematika, 1(1), 25-31.

Mantra, I. B. (2000). Demografi Umum. Yogyakarta: Pustaka Pelajar.

Ubro, M. H., Krisnata, R., \& Wiji Nogroho. (2017). Mobilitas Sirkuler di Indonesia.

Utomo, P. (2009). Dinamika pelajar dan mahasiswa di sekitar kampus Yogyakarta (Telaah Pengelolaan rumah kontrak dan rumah sewa). 1-16. Yogyakarta. 